\title{
Effects of an e-learning programme on osteopaths' back pain attitudes: a mixed methods feasibility study
}

\author{
Jerry Draper-Rodi ${ }^{1 *}$ (D, Steven Vogel ${ }^{1}$ and Annette Bishop ${ }^{2}$
}

\begin{abstract}
Background: The biopsychosocial model is recommended in the management of non-specific low back pain but musculoskeletal practitioners can lack skills in assessing and managing patients using a biopsychosocial framework. Educational interventions have produced equivocal results. There is a need for an alternative educational tool to support practitioners' development in the application of biopsychosocial model to manage low back pain.

Methods: A mixed methods study assessed the feasibility and acceptability of an e-learning programme on the biopsychosocial management of non-specific low back pain for osteopaths with more than 15 years' experience. A sequential explanatory design was conducted, with a feasibility randomised controlled trial and semi-structured interviews explored with thematic analysis.

Results: A total of 45 participants participated in the RCT of which 9 also participated in the interview study. The apriori sample size was not met (45 instead of 50). The recruitment strategies, randomisation, retention, data collection and outcome measures worked well and were found to be feasible for a main trial. The retention, satisfaction and participants' views of the programme demonstrated a good acceptability of the programme. Data from the semi-structured interviews were organised in three themes, the first two were related to the feasibility and acceptability of the e-learning programme (practical experience of following the course and engagement with the content) and the third relates to the impact of the intervention (perception of the BPS model).

Conclusion: A main RCT is feasible and the intervention was received well by the participants. A main RCT is required to assess the effectiveness of the e-learning programme. This work also provided data on aspects so far unreported, including osteopaths' views on continuing professional development, on e-learning as a form of continuing professional development and osteopaths' perceptions and challenges concerning the implementation of the biopsychosocial model in practice.
\end{abstract}

Keywords: Biopsychosocial, Continuing professional development, Non-specific low back pain, Osteopathy, Manual therapy, Feasibility, Randomised controlled trial

\footnotetext{
* Correspondence: Jerry.Draper-Rodi@uco.ac.uk

'University College of Osteopathy, 275 Borough High Street, London SE1 1JE,

UK

Full list of author information is available at the end of the article
}

(c) The Author(s). 2021 Open Access This article is licensed under a Creative Commons Attribution 4.0 International License, which permits use, sharing, adaptation, distribution and reproduction in any medium or format, as long as you give appropriate credit to the original author(s) and the source, provide a link to the Creative Commons licence, and indicate if changes were made. The images or other third party material in this article are included in the article's Creative Commons licence, unless indicated otherwise in a credit line to the material. If material is not included in the article's Creative Commons licence and your intended use is not permitted by statutory regulation or exceeds the permitted use, you will need to obtain permission directly from the copyright holder. To view a copy of this licence, visit http://creativecommons.org/licenses/by/4.0/ The Creative Commons Public Domain Dedication waiver (http://creativecommons.org/publicdomain/zero/1.0/) applies to the data made available in this article, unless otherwise stated in a credit line to the data. 


\section{Key messages regarding feasibility}

- It was uncertain if an e-learning course could be used to train osteopaths to the biopsychosocial model. It was also uncertain if enough osteopaths could be recruited and if the outcome measures would be acceptable.

- The participants accepted well the e-learning course and were satisfied with its content and duration.

- Recruitment strategies and outcome measures could be used in a main trial. The e-learning course was a suitable option as a form of CPD which could be used in a main trial.

\section{Background}

The biopsychosocial (BPS) model has been recommended in the management of non-specific low back pain (NSLBP) for nearly 15 years $[12,54,55]$ as NSLBP is multifactorial and BPS factors, such as sleep disorder or depression, are shown to predict pain and disability outcomes [19, 20, 27, 61]. These factors have become targets for intervention [36, 76]. Weighting of factors vary between cases and therefore the expectation is that practitioners are fluent and flexible in their approach in order to most effectively manage patients [13]. This is usually explained as the practitioners' approach being on a continuum (see Fig. 1 informed by Sacristán [64]). One end being a biomedical orientation is: "a mechanistic view of the body, in which illness is simply a fault in the machine that should be fixed" [81] "and any psychologic element being relatively unimportant or secondary to the physical disorder" [80].

The other end of the continuum being a biopsychosocial one: "a model of human illness (rather than disease) that includes biological, psychological and social dimensions, and the interactions between them" [81].

A practitioner's orientation can be measured with various instruments, including the Pain Attitudes and Beliefs Scale (PABS) [57] and the Attitudes to Back Pain Scale in Musculoskeletal Practitioners (ABS-mp) [60]. Collectively, manual therapists report a lack of training on BPS assessment and management and express a need for training in this field [24, 68, 71, 82]. Attempts to train manual therapists in the BPS model have had varied results, many with little effect on patient outcomes $[29,38$, 58, 69]. Problems identified include interventions being too short (less than $5 \mathrm{~h}$ ), a lack of needs and content analyses prior to developing the training resource, using small sample sizes (the threshold to observe attitudinal change is 42 participants), absence of explicit use of behavioural change frameworks and poor description of interventions; a common issue with randomised controlled trials [48]. More recent attempts to train practitioners in a BPS approach have been more successful in physiotherapy/physical therapy [2, 4, 31, 59, 70, 78, 79]; however, it remains unclear how best to enhance practitioners' ability to deliver care using a BPS approach. There is therefore a need to develop and test educational interventions in this field. Osteopaths work mostly independently and tend to be isolated geographically and professionally [23]. Developing CPD to support access to evidence and good practice has been recommended to the regulator of osteopathy [45] and e-learning offers increased accessibility to education, efficacy, cost effectiveness, learner flexibility and interactivity [67], is the fastest growing trend in educational uses of technology [39] and is a mode of delivery that follows good practice advice for medical education [18]. E-learning has not yet been tested for helping manual therapists to use a BPS approach with their patients.

\section{Aim/objectives}

Following the Medical Research Council's guidance for the development of complex interventions [15], the aim of this study was to assess the feasibility of a main RCT and the acceptability of using an e-learning programme to train osteopaths in the BPS management of NSLBP, who had not been exposed to the BPS model during their undergraduate training. To avoid self-selection bias by osteopaths with a particular interest in BPS, participants were not asked if they had trained in BPS as part of the recruitment process.

Mixed methods were used as recommended in the assessment and/or creation of e-learning programmes in healthcare $[10,62,77]$.

\section{Methods}

Guidelines on the conduct of mixed methods research to address processes affecting implementation of evidence-based interventions informed the design of this mixed methods sequential explanatory study [17, 26]. The design was based on a trial with a similar aim, i.e. to assess the effectiveness of a BPS programme on practitioners' attitudes [59]. The research was approved by the University Research Ethics Committee. The trial was not registered.

\section{Quantitative strand}

This is reported in line with the CONSORT guidelines [49].

\section{Trial design}

The study was a feasibility RCT with a parallel design (see Fig. 2) to control for confounding factors external to the study. The allocation ratio between the intervention group and the control group was 1:1. There were no important changes to the methods after the trial started. 


\begin{tabular}{|c|c|}
\hline Body orientated & Person orientated \\
\hline $\begin{array}{c}\text { clinical reasoning based on } \\
\text { normative views of biological } \\
\text { variables }\end{array}$ & $\begin{array}{l}\text { Introduction of psychosocial } \\
\text { factors into clinical } \\
\text { assessment }\end{array}$ \\
\hline $\begin{array}{l}\text { Disease or symptom } \\
\text { orientated care }\end{array}$ & $\begin{array}{l}\text { Person orientated care } \\
\text { (beyond the consultation) }\end{array}$ \\
\hline $\begin{array}{l}\text { Focus on profession's / } \\
\text { clinician's agenda }\end{array}$ & $\begin{array}{l}\text { Focus on outcomes of } \\
\text { importance to person }\end{array}$ \\
\hline $\begin{array}{l}\text { Person's perspectives } \\
\text { secondary or ignored }\end{array}$ & $\begin{array}{c}\text { Person's values, preferences, } \\
\text { beliefs taken into account }\end{array}$ \\
\hline Patient passive & $\begin{array}{l}\text { Patient active and } \\
\text { empowered }\end{array}$ \\
\hline $\begin{array}{c}\text { Underpinned by ethical } \\
\text { principles of beneficence and } \\
\text { paternalism }\end{array}$ & $\begin{array}{l}\text { Underpinned by ethical } \\
\text { principle of autonomy and } \\
\text { justice }\end{array}$ \\
\hline $\begin{array}{l}\text { Biomedical } \\
\text { practice }\end{array}$ & $\begin{array}{r}\text { Biopsychosoc } \\
\text { practi }\end{array}$ \\
\hline
\end{tabular}

Fig. 1 Continuum of practice (the components on the left side of the vertical line correspond to a biomedical style of practice; on the right side to a biopsychosocial one. Note that practitioners may present a mixture of right- and left-side components in their practice resulting in an overall practice style falling somewhere on the continuum). Figure informed by Sacristán [64]

\section{Participants}

To be eligible for the study, participants had to:

- Be an osteopath practising in the UK

- Have a minimum of 15 years' practice experience; undergraduate curricula have integrated BPS principles in recent years but experienced osteopaths would not have been trained on this model during their undergraduate training
- Not have been involved in osteopathic education in the last 10 years

Those eligible and agreeing to take part provided written consent.

\section{Recruitment}

The 6-week recruitment period started on 01/09/2015 accessing a national sampling frame via a number of 


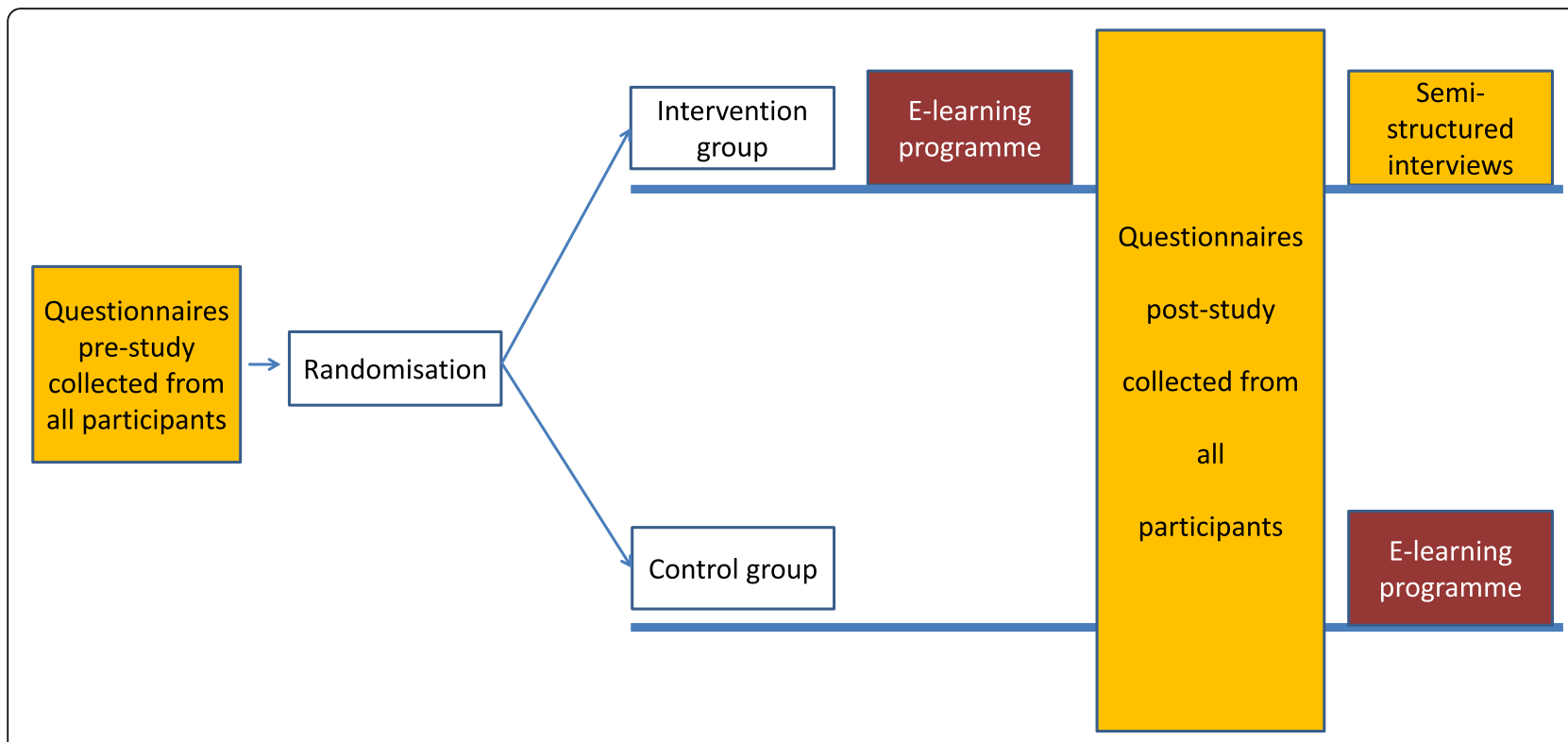

Fig. 2 Study design

different recruitment strategies. Emails to osteopaths randomly selected from the General Osteopathic Council database of those indicating availability to be contacted for research purposes, and additional direct contact was made with regional groups. The National Council for Osteopathic Research disseminated information about the opportunity to take part through social media and regional research hubs were also invited to alert their members. Adverts in professional journals also appeared. The wording chosen presented the material in a factual manner in order to avoid self-selection bias by those with a particular interest in BPS. Prospective participants who expressed an interest contacted the principal investigator who sent a participant information sheet and consent form in an email approved by the research ethics committee. No financial incentives were offered to take part.

\section{Intervention}

The intervention was developed for participants who had significant clinical experience but more limited exposure to contemporary evidence and little exposure to the concepts underpinning the BPS model. This had been explored qualitatively prior to the development of the e-learning programme and a need had been found to close the theory-practice gap, requiring specific training to change manual therapists' attitudes to back pain, knowledge, skills and confidence to assess and manage patients within a BPS framework. Findings were similar across different manual therapy professions [24, 82]. The e-learning programme for this study was developed by an osteopath (JDR) and the content was audited by two BPS experts: an osteopath (SV) and a physiotherapist
(AB). Its development is detailed elsewhere [19, 20] but, in summary, it involved applied theories that informed different stages (see Fig. 3). The theoretical underpinning included results from a scoping review $[19,20]$, the behavioural change model [47] and educational theories; and the e-learning was arranged following the ADDIE stages model of e-learning programmes.

The e-learning was developed using a Moodle platform and included lectures, interactive case scenarios and quizzes. Its duration was $8 \mathrm{~h}$ informed by the ADDIE development phase. Each lecture was maximum 30 min to enhance participants' experience. There was no formal interaction between the research team and the participants. Participants could, however, email the research team if needed. It was organised into 5 units (see Fig. 4): unit 1 provided general information on NSLBP and the BPS model; unit 2 focused on historytaking; unit 3 on clinical examination; unit 4 integrated the content of the previous units using clinical scenarios and unit 5 discussed broader management considerations. Access to each unit was granted once the previous unit had been completed (the content was not graded but participants had the option to retake quizzes after reading feedback on their answers). The e-learning also included an extra-content material section where participants could access resources and materials to further their knowledge on a topic.

All participants were informed that the course would require a total of $8 \mathrm{~h}$ over 6 weeks. The intervention group was invited to take the e-learning programme on $19 / 10 / 2015$, whilst the control group participants were informed they had to wait for the other group to complete the e-learning programme and their starting 
Influences on the e-learning programme: scoping review (violet arrows), behavioural change wheel (blue arrows), and educational theories (yellow arrows for cognitive behaviourism, red arrows for social constructivism and green arrows for connectivism). The thick arrow represents the influences the scoping review results had on how the behavioural change wheel model was used.

E-LEARNING PROGRAMME

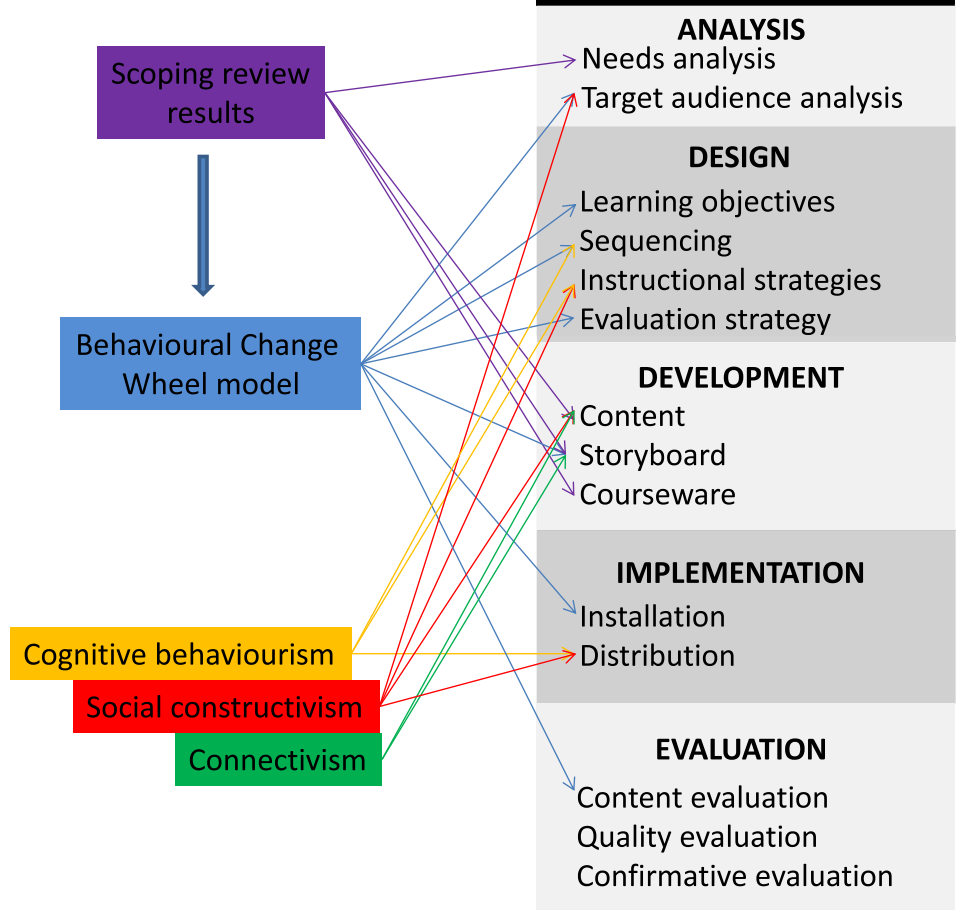

Fig. 3 Intervention development

date, 06/12/2015. They were managing their patients as usual during that time. They all had 6 weeks to complete the e-learning programme. Participants' engagement with the module was monitored once a week using the e-learning programme administration panel on the elearning programme website. Participants were contacted by email after seven consecutive days without logging in, over the phone after 14 days, and by text message after 21 days.

\section{Data collection}

At baseline, all participants were asked to complete the initial questionnaire that included participant characteristics and two validated attitudinal measures (not explicitly named in the questionnaire): the Pain Attitudes and Beliefs Scale (PABS) [57] and the Attitudes to Back Pain Scale in Musculoskeletal Practitioners (ABS-mp) [60] that have acceptable psychometric properties $[5,7,8,32$, 33, 52, 57, 75] (see Table 1).
Participants were invited post intervention, to complete a follow-up questionnaire which included the attitudinal measures and a short satisfaction survey on the e-learning programme assessing their satisfaction with the e-learning programme, their interest in the elearning programme, new perspectives on NSLBP and the clarity of teaching of the e-learning programme.

\section{Sample size}

Following guidance on participant numbers for feasibility studies $[14,42]$ and on how feasibility RCTs can provide reliable standard deviation estimates for a power calculation [66], a total sample of 50 participants was sought for inclusion in the feasibility RCT.

\section{Randomisation}

The randomisation procedure was implemented by the unblinded principal investigator using the RAND function in Excel which generated a random number sequence used to allocate participants to groups. 


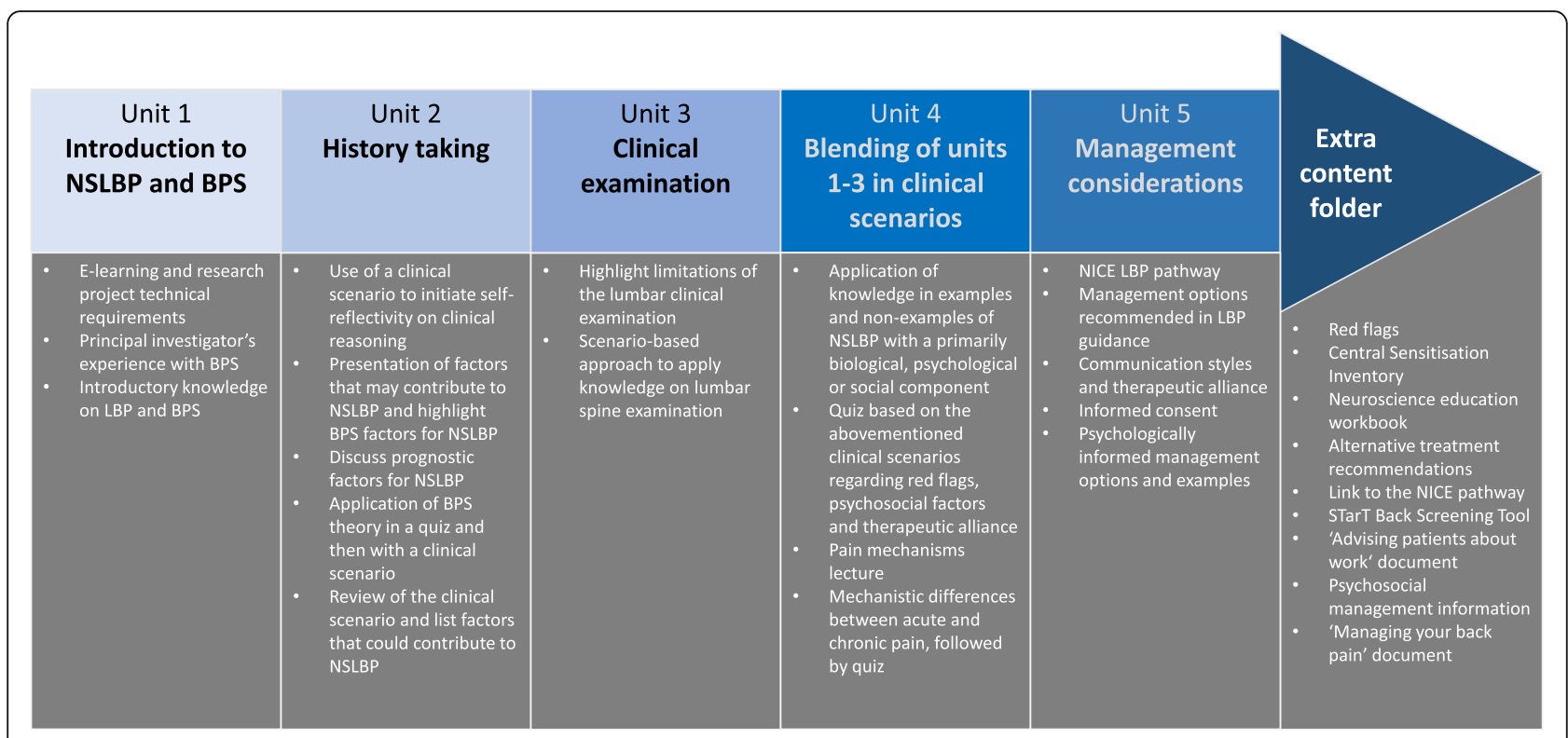

Abbreviations: BPS: biopsychosocial; LBP: low back pain; NICE: National Institute of Clinical Excellence; NSLBP: non-specific low back pain

Fig. 4 E-learning content (the arrow follows the sequencing of the units. The units were instructor-led)

Table 1 ABS-mp and PABS subscales (the last column is specific to this research project which aimed to change participants' attitudes to back pain)

\begin{tabular}{|c|c|c|c|c|}
\hline Scale name & Subitems & Subitem detail & Score & $\begin{array}{l}\text { Predicted direction of change in } \\
\text { intervention arm }\end{array}$ \\
\hline \multirow[t]{8}{*}{ ABS-mp } & \multicolumn{4}{|c|}{ Personal interaction consists of four factors } \\
\hline & LS & $\begin{array}{l}\text { Limitations on sessions, items about practitioners' policy towards } \\
\text { limiting the length of treatment (four items). }\end{array}$ & 28 & Unknown \\
\hline & PS & $\begin{array}{l}\text { Psychological, items measuring practitioners' willingness to } \\
\text { engage with psychological issues with their patients (four items). }\end{array}$ & 28 & Unknown \\
\hline & $\mathrm{CHS}$ & $\begin{array}{l}\text { Connection to healthcare system, items measuring practitioners' } \\
\text { perception of the health-care system and provision of available } \\
\text { services (three items). }\end{array}$ & 21 & Unknown \\
\hline & $\mathrm{CC}$ & $\begin{array}{l}\text { Confidence and concern, items measuring practitioners' } \\
\text { confidence and concern about treatment and clinical limitations } \\
\text { in themselves and others (two items). }\end{array}$ & 14 & Unknown \\
\hline & \multicolumn{4}{|c|}{ Treatment orientation consists of two factors } \\
\hline & RA & $\begin{array}{l}\text { Re-activation, items that concern return to work and to daily } \\
\text { activity and increasing mobility (three items). }\end{array}$ & 21 & $\uparrow$ \\
\hline & BM & $\begin{array}{l}\text { Biomedical; items that concern advice to restrict activities and } \\
\text { to be vigilant, and the belief that there is an underlying } \\
\text { structural cause of back pain ( } 3 \text { items). }\end{array}$ & 21 & $\downarrow$ \\
\hline \multirow[t]{2}{*}{ PABS } & Biomedical & $\begin{array}{l}\text { Practitioner believes in a biomechanical model of disease, } \\
\text { where disability and pain are consequences of specific } \\
\text { tissue pathology and treatment is aimed at treating the } \\
\text { pathology }\end{array}$ & 10 & $\downarrow$ \\
\hline & Behavioural & $\begin{array}{l}\text { Practitioner believes in a biopsychosocial model of disease, } \\
\text { in which pain does not have to be a sign of tissue damage } \\
\text { and can be influenced by social and psychological factors }\end{array}$ & 9 & $\uparrow$ \\
\hline
\end{tabular}




\section{Blinding}

Participants and the researcher who collected and analysed the data were not blinded to group allocation. This research was part of doctoral work and the PI conducted all the different stages of the work to gain experience in different aspects of trial research.

\section{Statistical methods}

All statistical analyses were performed using IBM SPSS version 22 (IBM Corp, Armonk, New York). Being a feasibility study, the analysis was descriptive and focused on mean difference and $95 \%$ confidence intervals and not on inferential testing [41-43, 50, 73]. The survey data were summarised using medians, interquartile ranges and percentages. An open text question asking about the 'Three most useful things learnt' was analysed using content analysis [28] where items were counted to list and rank the participants' views on the most useful things learnt. Frequencies reported the number of individual participants who mentioned a particular theme, rather than the number of times themes were mentioned, to prevent over representation of individual participants who could mention a theme several times [53].

\section{Qualitative strand}

Semi-structured interviews were used to collect more indepth views and opinions on the e-learning programme from a convenience sample drawn from the intervention group.

\section{Participants}

All participants from the intervention group were sent an invitation inviting them to take part in an interview conducted using a voice-over-IP service (such as Skype ${ }^{\circ}$ ) with video feature based on participants' previous experience and preferences. Before recording, the consent form content was discussed, participants were reminded they could withdraw at any time without needing to give reasons, and to keep the interview content confidential. Participants were informed that a device was used to record the interview and when it was turned on. At the end of the interview, the participant was thanked and offered the opportunity to review and amend the transcript before it was used in the analysis. The researcher stopped the online conversation.

\section{Data collection and analysis}

An interview guide was used during the interviews to gather participants' views on the intervention itself (see Table 2) and to explore if and how the e-learning intervention had an impact on their practice. The interview was transcribed using a six-step reflexive, iterative process of data management [28] and analysed with both content and thematic analyses $([9,16,53]$, p. 251 and
433, [34]). The data were coded identifying themes or patterns. Themes were then reviewed and refined [9] in order to identify key themes, areas of consensus and differences of opinion between participants. Data triangulation was used to assess saturation ([17], p. 251 and 433, [34]). Audiotapes were used to identify illustrative quotes to illustrate themes.

\section{Results}

A total of 45 participants took part in the feasibility RCT: 23 were randomly allocated to the intervention group and 22 to the control group. The demographics of the participants in both groups are presented in Table 3-the main difference between the groups was their special interest in LBP: the intervention group had twice as many as the control group. Recruitment and participant flow are reported in Fig. 5.

\section{Qualitative strand}

Nine participants from the intervention group took part in the semi-structured interviews. The participants' demographics are shown in Table 4.

\section{Feasibility of a main trial}

To assess the feasibility of a main trial, Table 5 describes the integrity of the study protocol; specifically, the feasibility of the recruitment strategies, the recruitment and retention rates, the randomisation procedure, data collection and outcome measures. This mixed methods study followed the protocol that would be followed for a larger trial, including inclusion/exclusion criteria, and intervention preparation and testing.

Feasibility and acceptability of the e-learning programme The feasibility and acceptability of the e-learning programme are presented using the satisfaction survey results and the participants' views on the e-learning programme.

\section{Satisfaction survey}

Twenty-one out of 23 participants from the intervention group answered the survey at the end of the e-learning programme. The responses to the satisfaction questions are summarised in Fig. 6, which show high levels of satisfaction. No participant rated the course as unsatisfactory, teacher clarity or course interest as less than very good.

All but one participant $(n=20)$ responded to the question stating the three most useful things learnt during the e-learning programme. Content analysis suggested 3 categories: answers related to pain theory (21), to patient management (18) and to BPS influences and diagnosis (18). 
Table 2 Interview guide

\section{TIME}

- How have you organised your working week to fit the course?

- How long did you spend online on the e-learning course per week?

- How did you organise accessing the course over the 6 weeks?

- What types of things and how much time if at all did you devote to offline work related to the course?

\section{MODE OF DELIVERY}

- Could you tell me what you thought about taking the course online?

- OK, and tell me about your experience of accessing the course online.

- Help me understand your practical experience of taking part - for example tell me about from where you accessed the course.

\section{CONTENT}

- What did you think of the content of the course? (Good vs bad)

- Tell me what you thought about the coverage of the course (the topics covered)? What was covered particularly well? Was there material missing?

- Now we've talked about the content, what about the level/accessible/detail of it: How accessible was it - in terms of the level of information?

- What about the extent of interactivity in the course? Can you give me an example of interactivity that worked well and example that didn't work so well?

\section{CONTENT - BPS}

- To wrap up, a lot of the course was about the biopsychosocial model. What are your views of the BPS model in practice? (Experience of cases that changed since the course)

Table 3 RCT participants' characteristics

\begin{tabular}{lll}
\hline & $\begin{array}{l}\text { Intervention group } \\
(\boldsymbol{n}=\mathbf{2 3})\end{array}$ & $\begin{array}{l}\text { Control group } \\
(\boldsymbol{n}=\mathbf{2 2})\end{array}$ \\
\hline Female $\mathrm{n}(\%)$ & $30-39(n=1)$ & $30-39(n=2)$ \\
$\begin{array}{l}\text { Age group } \\
\text { (number of participants) }\end{array}$ & $40-49(n=9)$ & $40-49(n=9)$ \\
& $50-59(n=12)$ & $50-59(n=7)$ \\
& $60-69(n=1)$ & $60-69(n=4)$ \\
& $4.00^{\mathrm{a}}(1.00)^{\mathrm{b}}$ & $3.50(1.00)$ \\
Median (IQR) & $(50-59)$ & $(40-49)$ \\
& $21.91(5.74)$ & $23.45(5.26)$ \\
Years in practice Mean (SD) & $14(61 \%)$ & $6(27 \%)$ \\
\hline Special interest in LBP $\mathrm{n}(\%)$ & $140-39$
\end{tabular}

\section{Participants' views on the programme}

Data from the semi-structured interviews were organised in three themes. The first two themes are presented in Table 6, Practical experience of following the course and Perception of the content, and the third follows in the 'Impact of the e-learning programme' section, which uses both quantitative and qualitative data.

Impact of the e-learning programme Participants' perceptions of the BPS model

The final theme emerging from the interview data characterised study participants' perceptions of the BPS model and was formed of the three sub-themes BPS model is not structural enough, BPS model is part of existing practice, and Transformative. These perceptions are presented below with illustrative quotations. This is 


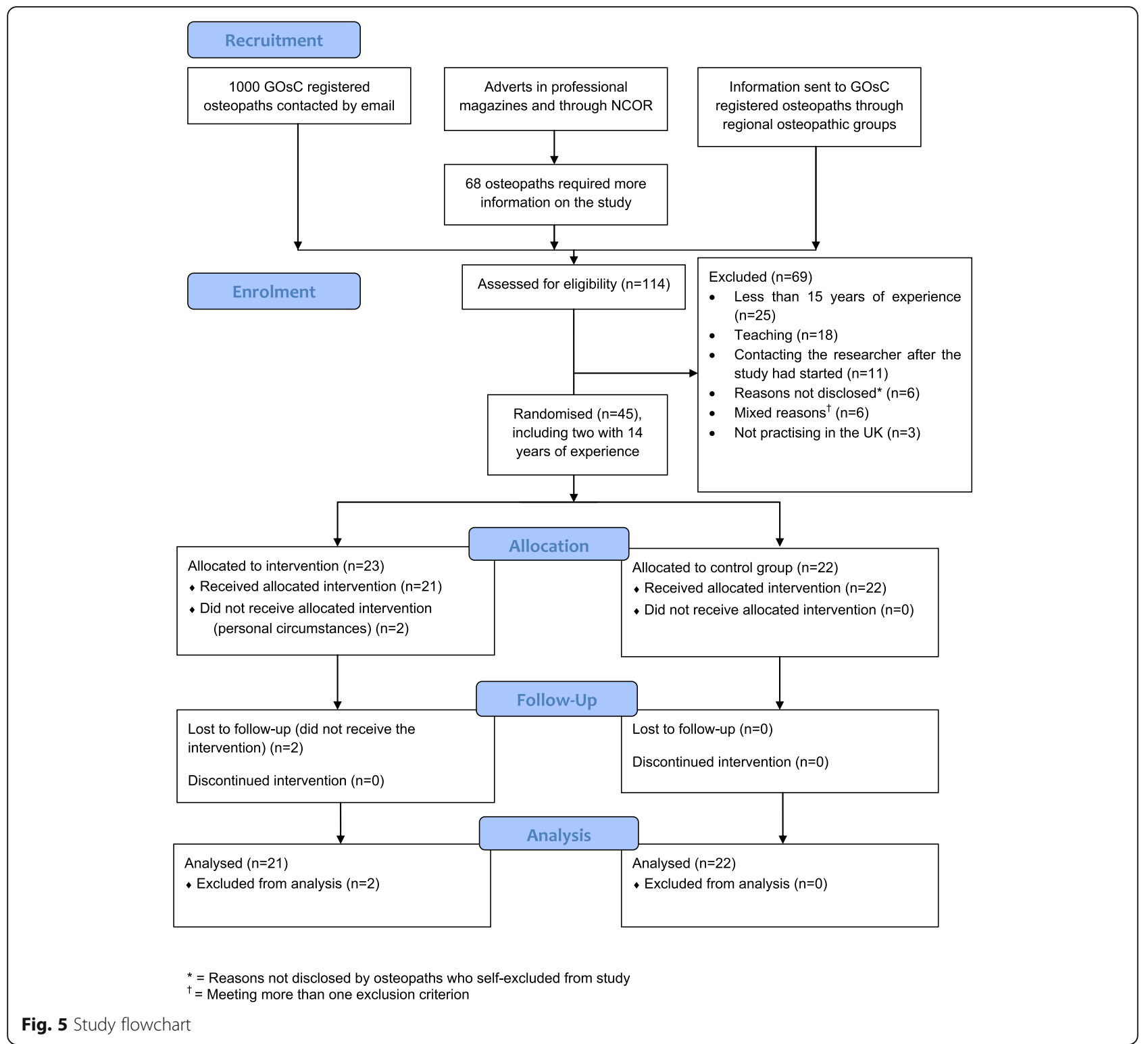

not to suggest that all participants fitted distinctly in each sub-theme (as there was some overlap) but rather it offers a broad, differentiation of participants' perceptions.

\section{BPS model is not structural enough}

One view of the BPS model was that it was not sufficiently based on biomechanical and anatomically focussed care (aka as structural approach). It was perceived as a model where musculoskeletal problems were either systemic (red flags) or psychosocial (yellow, blue and black flags) with no space for simple mechanical aetiology.

"There is a psychological element to it, there's a social element to it but there's also possibilities of physical problems which are not pathological but are not psychological or social". Participant A
This lack of a structural aspect led to a sense that osteopathy was devalued in the content of the e-learning programme.

"There was a general tone of - I would quite often you know this thing about I'm going to go and shoot myself now then - what am I doing as an osteopath? You know? There was a general tone of devaluing what osteopaths do". Participant A

\section{BPS model is part of existing practice}

The BPS model was viewed as a model of practice that was already used and familiar to osteopaths.

"I think intuitively a lot of osteopaths do follow some of the concepts [of the BPS model]" Participant G 
Table 4 Semi-structured interview participants' characteristics

\begin{tabular}{lllll}
\hline ID & Gender & Age group & Years in practice & Special interest in LBP \\
\hline 107705 & Female & $50-59$ & 26 & Yes \\
117268 & Male & $40-49$ & 25 & Yes \\
215827 & Female & $50-59$ & 23 & Yes \\
375469 & Male & $50-59$ & 29 & No \\
410737 & Female & $40-49$ & 17 & Yes \\
431276 & Male & $60-69$ & 31 & Yes \\
532034 & Male & $50-59$ & 17 & Yes \\
539532 & Female & $40-49$ & 18 & No \\
878115 & Female & $40-49$ & 23 & Yes
\end{tabular}

Whilst there were no disagreements with the content, there was a feeling that the content was not bringing a new perspective to osteopaths on back pain.

"Some of the psychological and psychosocial stuff I think a lot of older people that are reasonably experienced, I think we do it anyway" Participant A

\section{Transformative}

The last category saw the BPS model as a better model than the biomedical, and one that was suitable a meta framework for practice.

"That [BPS] model works better for me than the biomedical one which actually has always been a bit of a struggle to know 'is it facet?' 'is it disc?"' Participant I

The BPS model was seen as offering a novel approach to back pain. It had not been taught during undergraduate education despite experience of subjects such as psychology or diet. Participants described isolated topics presented in a mechanistic nature and not integrated in clinical practice.

"That's something I wasn't taught a great deal at undergraduate when I was a student although I've heard about it postgradutately (sic). The Flags were new to me so I found that very helpful". Participant B

"[The content] was very good, very thorough. It was an aspect of diagnosis I hadn't learned in college so it did make me think. It challenged the way I had been taught" Participant E

It also had the merit of being evidence-based rather than experience-based.

"It was very helpful, it was drawing on research because so much we're told, or what I was told in my training was basically experiential" Participant $\mathrm{H}$
The BPS model offered a structure to assess and manage patients with, e.g. the flag system and a system to integrate the different aspects of a patient's life. It also helped patients' management.

"It has made me think a bit more about the various factors which do come to play in a person's problems which would stop them getting better. Since doing the course I have identified people who had put perhaps psychological barriers up to their progress or to advice on exercises". Participant E

Participants became more aware of the risks of increasing patients' negative attitudes to back pain. To prevent this, participants changed their communication content and style with patients.

"[The course] has changed in some of the language maybe that I would use with patients and just reemphasizing thought positives and maybe not using quite so much medicalised language". Participant I

The BPS model also offered a common language with other professionals.

"It seems to be absolutely everywhere at the moment. It seems to be the way the NHS is going in this country, the way physios are going in this country so I think it's something we need to embrace - that we need to be very aware of". Participant I

\section{Questionnaire data}

There was little difference in the means and standard deviations on the six ABS-mp domains and the two PABS domains for the intervention and control groups at baseline.

Between-group changes on the ABS-mp show that 3 domains had mean differences with confidence interval ranges that did not include the value of no effect: LS, PS and $\mathrm{BM}$; and on the PABS both domains had mean 
Table 5 Feasibility criteria

\begin{tabular}{|c|c|c|c|}
\hline & A priori feasibility criteria & Feasibility threshold met? & Considerations for future trial \\
\hline \multirow{6}{*}{$\begin{array}{l}\text { Recruitment } \\
\text { strategies } \\
\text { feasibility }\end{array}$} & $\begin{array}{l}\text { Journals agreeing to publish the } \\
\text { recruitment ad for free }\left(^{(}\right)\end{array}$ & Both professional journals accepted & \multirow{6}{*}{$\begin{array}{l}\text { It is not possible to provide an accurate } \\
\text { recruitment rate as some of the advertising } \\
\text { media contacted osteopaths indirectly and s } \\
\text { the denominator is unknown. }\end{array}$} \\
\hline & $\begin{array}{l}\text { Regional groups accepting to } \\
\text { forward messages to their } \\
\text { members }\end{array}$ & All regional groups accepted & \\
\hline & $\begin{array}{l}\text { National Council for Osteopathic } \\
\text { Research (NCOR) accepting to } \\
\text { inform their members about the } \\
\text { research project }\left(^{(}\right)\end{array}$ & $\begin{array}{l}\text { NCOR informed their members and } \\
\text { mentioned the study when doing talks to } \\
\text { regional groups }\end{array}$ & \\
\hline & Ads published on time $\left({ }^{a}\right)$ & $\begin{array}{l}\text { Journal ads were published on time for } \\
\text { readers to have time to contact the PI if } \\
\text { interested to have more information }\end{array}$ & \\
\hline & $\begin{array}{l}\text { Gaining access to GOsC members' } \\
\text { email addresses who accepted to } \\
\text { be contacted for research purpose } \\
\left({ }^{a}\right)\end{array}$ & $\begin{array}{l}\text { Access to } 1000 \text { email addresses was granted } \\
\text { by the PI's institution }\end{array}$ & \\
\hline & $\begin{array}{l}\text { Mail Merge system allowing to do } \\
\text { mass emailing }\left({ }^{a}\right)\end{array}$ & $\begin{array}{l}1000 \text { emails were sent with no issue with the } \\
\text { system }\end{array}$ & \\
\hline $\begin{array}{l}\text { Recruitment and } \\
\text { retention } \\
\text { feasibility }\end{array}$ & Recruiting 50 participants $\left({ }^{a}\right)$ & $\begin{array}{l}\text { Only } 45 \text { were recruited. As only } 43 \text { met the } \\
\text { eligibility criteria, two with } 14 \text { years in } \\
\text { practice were included. }\end{array}$ & $\begin{array}{l}\text { - Reassess eligibility criteria owing to their } \\
\text { strictness } \\
\text { - Consider recruiting other Allied Health } \\
\text { Practitioners with similar scope of practice } \\
\text { - Consider having a longer recruitment } \\
\text { period ( } 12 \text { prospects contacted the PI } \\
\text { within the following } 4 \text { months). }\end{array}$ \\
\hline
\end{tabular}

Enough participants accepting to be interviewed to reach data saturation $\left(^{b}\right)$

Participants sending back consent forms $\left({ }^{a},{ }^{b}\right)$

Reaching an $80 \%$ retention rate ${ }^{a}$, b)

Receiving questionnaires back from participants ( ${ }^{\mathrm{a}}$ )

To send questionnaires in a format easy to access and fill in by all participants $\left({ }^{\mathrm{a}}\right)$

Using voice-over-IP service successfully $\left({ }^{b}\right)$

Being able to record the interviews $\left({ }^{b}\right)$

Interview guide suitable ${ }^{(b)}$

Participants agreeing to fill in questionnaires $\left({ }^{a}\right)$
10 participants agreed to be interviewed, 9 were needed to reach data saturation.

Consent forms were received from all participants

91\% (41/45) for the Quant strand, and 90\% for Qual strand $(9 / 10)$

Post-intervention questionnaires were completed by 43 participants (96\%): 2 participants in intervention group did not complete the course (details in text below) nor questionnaires despite invitation. All control group participants completed the questionnaires

Questionnaires sent in Word@ were protected to ensure participants could not change the content of the questionnaires. This led to compatibility problems.

Yes

One recording was faulty. Field notes were used to write up a transcript that the interviewee checked within three hours of the interview. No excerpts were used from this interview.

Provided useful content and was well accepted by participants

Participants accepted the questionnaires well. Some were surprised about the similarities of the questions across the two validated measures included.
High retention rate achieved by sending reminders to participants: up to seven reminders per participant when not accessing the e-learning

Alternative systems should be considered. 
Table 5 Feasibility criteria (Continued)

\begin{tabular}{|c|c|c|c|}
\hline & A priori feasibility criteria & Feasibility threshold met? & Considerations for future trial \\
\hline & $\begin{array}{l}\text { Control group accepting to fill in } \\
\text { questionnaires twice before taking } \\
\text { the course, } 6 \text { weeks apart }\left({ }^{(}\right)\end{array}$ & All sent back the completed questionnaires & \\
\hline & $\begin{array}{l}\text { Suitability of the reflexive iterative } \\
\text { process of data management }\left({ }^{b}\right)\end{array}$ & $\begin{array}{l}\text { The process was feasible and satisfactory and } \\
\text { was well accepted. }\end{array}$ & \\
\hline $\begin{array}{l}\text { Acceptability } \\
\text { and feasibility of } \\
\text { the outcome } \\
\text { measures }\end{array}$ & $\begin{array}{l}\text { Suitability of attitudinal } \\
\text { questionnaires }\left({ }^{(}\right)\end{array}$ & $\begin{array}{l}\text { Some participants expressed their surprise } \\
\text { about the similarities of the questions across } \\
\text { the two validated measures included }\end{array}$ & \\
\hline Threshold met & Threshold partly met & Threshold not met & \\
\hline
\end{tabular}

${ }^{\mathrm{a}}$ Quant strand, ${ }^{\mathrm{b}}$ Qual strand

differences with confidence interval ranges that did not include the value of no effect.

Table 7 details within group and between group changes in attitudinal measures.

\section{Discussion}

This feasibility study found that overall using an elearning programme to train experienced osteopaths to the BPS model regarding NSLBP was acceptable and feasible in all points, except for the recruitment as the a-priori number of participants was not reached.

\section{Feasibility of a main trial Recruitment}

The recruitment strategy included the use of several different media to assess if this could provide enough participants in a main trial. It was found that all media were satisfactory; however, further more collaborative efforts with copy editors are recommended to ensure that the material published is fully aligned with the required copy provided by the research team. Using phone calls or sending SMS could complement the recruitment strategies used as they are effective ways to increase recruitment rates [74] but careful consideration would need to be taken regarding practical, ethical and resource implications. Being a feasibility study, 50 participants were sought for the mixed methods feasibility study. Only 45 were recruited and this was largely due to the strict exclusion criteria. One exclusion criterion was to have not taught in the previous 10 years. This was based on a supposition that educators could have been exposed to the BPS model during their teaching. A recent qualitative study conducted in New Zealand [63] analysed video-recordings of the clinical management of patients with acute NSLBP by 3 osteopaths who graduated in the UK and were teaching in New Zealand. The model used by these participants includes clear signs of BPS management supporting the exclusion criterion choice. Another possible reason for the low recruitment rate might have been related to the recruitment period: 12 participants contacted the researcher after the study had started, up to 4 months later. For a further study, it would be recommended to extend the 2-month recruitment period and to carefully consider the exclusion criteria for recruiting more participants whilst weighing the risk of having a population that would not respond to the intervention. Another way to improve recruitment would be to enhance the description of the e-learning programme by including the possible effects of the elearning programme on clinical practice and the individual benefits for participants [22]. Low recruitment rates in trials are a common problem with less than a third

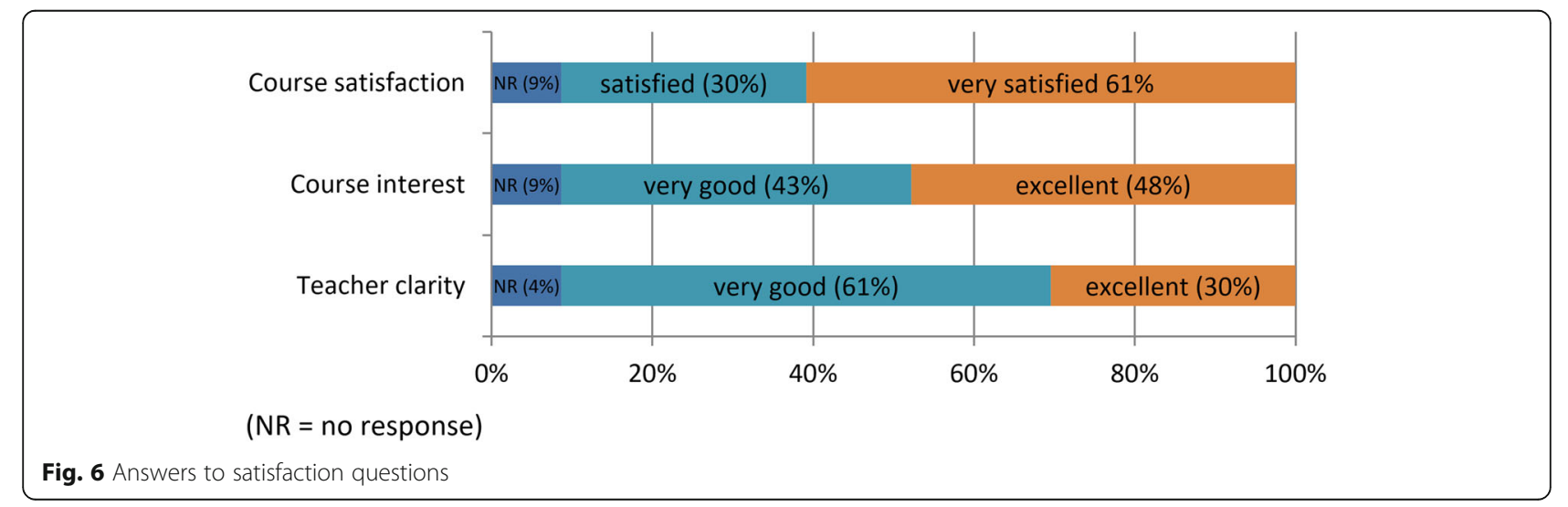


Table 6 Qualitative views on the e-learning programme (first two themes from semi-structured interviews presented in this table, third presented in-text below)

$\begin{aligned} & \text { Subtheme } \\ & \text { Theme 1: Practical experience of following the course }\end{aligned}$
$\begin{aligned} & \text { Time and } \\ & \text { setting }\end{aligned}$
$\begin{aligned} & \text { Time outside clinic time was favoured to not disturb clinic schedule. } \\ & \text { completed in chunks, at their own pace. }\end{aligned}$
$\begin{aligned} & \text { Practical } \\ & \text { aspects of the } \\ & \text { course }\end{aligned}$
$\begin{aligned} & \text { The mode of delivery of the course was well accepted by the participants. } \\ & \text { They we happy that it was online. }\end{aligned}$
$\begin{aligned} & \text { The e-learning programme was described as easy to access, including in } \\ & \text { Some minor difficulties were reported (e.g. slight confusion during initial } \\ & \text { connection for one participant; e-learning website down one half day } \\ & \text { when the hosting server was down; and one participant found not very } \\ & \text { clear how many lessons had been completed). } \\ & \text { The e-learning programme was described as well-presented and very easy } \\ & \text { to access from a laptop. One interviewee reported that the references font } \\ & \text { was too small to be read on tablets. The interactivity was thought to work } \\ & \text { well and the use of quizzes was particularly praised. }\end{aligned}$

\section{Theme 2: Perception of the content}

Engagement Participants found there was sufficient content, the e-learning programme with the was thorough whilst not being overwhelming and being accessible to the content participants with little academic background.

Illustrative quotation

"It worked better for me doing it in chunks" Participant

"It was very good, very convenient in the sense that I could do it from home or in my clinic if I wanted to. I didn't have to travel to a venue." Participant G

"Quizzes made me think and made me have to recall what I'd been looking at and listening to so I thought they were really good. They helped to reinforce the learning." Participant D

Participants were satisfied with the content and the coverage of the elearning programme and found the content clear.

\begin{abstract}
Quizzes were found helpful to engage with the content and made participants study and reflect. They helped the absorption of the information delivered. Seeing results was found gratifying.Consideration for quiz improvements: providing a record of previous attempts when participants take quizzes multiple times; distributing them more across the e-learning programme (e.g. Unit 5: management considerations had no quizzes); and using more learners' experience in the questions.
\end{abstract}

Extra work Nearly half of participants interviewed spent more than the estimated $6 \mathrm{~h}$ done taking the course (range from 8 to $12 \mathrm{~h}$ ).

The extra work also included the 'Extra content' folder, accessed by all but one of the participants. It also included taking notes and reading them back or taking screen pictures as memos and looking at them later. One participant mentioned that a handout would have been useful.
"A lot of content and it was very relevant to clinical you know to practice of osteopathy and the type of patients one sees. And you explained the concepts very well which being an older practitioner, someone that qualified a long time ago I guess a lot of these concepts were not around then so it was good to have your programme there which introduced a lot of these concepts in a very clear manner" Participant G

"There were things within the content that I'd certainly come across like the flags etc. before on other courses but actually it was a much more interesting approach to the flags that I've come across before" Participant I

"The last quarter [of the e-learning programme] I thought "Gosh there's a lot there" in the last chunk which I felt was clinically very relevant" Participant G

"I did go back to a couple of the modules just to understand them again. I did a couple of modules further on and I thought "oh I think I need to go back to the basics" so I went back to the earlier modules a couple of times" Participant E

"I estimate eleven hours [of online work]: I went back over bits; I made notes when I went along as well" Participant B achieving the recruitment of the number of participants initially planned [72]. A possible way forward for a further study would be to include practitioners from different manual therapy professions.

\section{Randomisation and data collection}

The randomisation process, using the RAND function in Excel, worked well and could be employed in a main trial. Baseline characteristics were balanced apart from the special interests between the groups. This may be due to the small sample size in this feasibility study and in a larger main RCT all baseline characteristics should be balanced. If baseline characteristics imbalance remains, it may be associated with the outcome [11] and should be accounted for in the analysis [21]. The retention rate was high, potentially due to having a highly selected sample. The impact on retention would need to be considered if the inclusion criteria were changed for a main trial. Using digital versions of the questionnaires to collect participants' answers was found adequate. Few participants decided to send hard copies. 
Table 7 Attitudinal questionnaires results (within-group and between-group)

\begin{tabular}{|c|c|c|c|c|c|c|c|c|c|}
\hline \multirow{3}{*}{ ABS-mp } & \multirow[b]{3}{*}{ LS } & \multirow{3}{*}{$\begin{array}{l}\text { Baseline } \\
17.4\end{array}$} & \multirow{3}{*}{$\begin{array}{l}\text { After } \\
13.8\end{array}$} & \multirow{3}{*}{$\begin{array}{l}\text { Mean difference } \\
\text { within group } \\
3.6\end{array}$} & \multicolumn{2}{|c|}{$\begin{array}{l}95 \% \text { confidence } \\
\text { interval of the difference }\end{array}$} & \multirow{3}{*}{$\begin{array}{l}\text { Mean differences } \\
\text { between groups } \\
2.2\end{array}$} & \multicolumn{2}{|c|}{$\begin{array}{l}95 \% \text { confidence } \\
\text { interval of the difference }\end{array}$} \\
\hline & & & & & \multirow{2}{*}{$\begin{array}{l}\text { Lower } \\
1.8\end{array}$} & \multirow{2}{*}{$\begin{array}{l}\text { Upper } \\
5.4\end{array}$} & & \multirow{2}{*}{ Lower } & \multirow{2}{*}{$\begin{array}{ll}\text { Upper } \\
4.3\end{array}$} \\
\hline & & & & & & & & & \\
\hline & LS & 18.4 & 17.0 & 1.4 & 0.1 & 2.7 & & & \\
\hline & PS & 20.5 & 22.6 & -2.1 & -3.1 & -1.1 & -2.2 & -3.5 & -0.9 \\
\hline & PS & 20.7 & 20.6 & 0.9 & -0.7 & 0.9 & & & \\
\hline & $\mathrm{CHS}$ & 10.0 & 9.6 & 0.4 & -1.0 & 1.7 & 0.4 & -1.2 & 2.0 \\
\hline & $\mathrm{CHS}$ & 11.6 & 11.6 & 0 & -1.0 & 1.0 & & & \\
\hline & CC & 8.3 & 8.7 & -0.3 & -1.4 & 0.7 & -0.8 & -2.1 & 0.4 \\
\hline & CC & 9.4 & 8.9 & 0.5 & -0.2 & 1.2 & & & \\
\hline & RA & 14.8 & 16.3 & -1.6 & -2.8 & -0.3 & -0.8 & -2.4 & 0.9 \\
\hline & RA & 14.2 & 15.1 & -0.8 & -0.2 & 0.3 & & & \\
\hline & BM & 13.5 & 9.3 & 4.2 & 3.1 & 5.4 & 4.1 & 2.8 & 5.4 \\
\hline & BM & 13.6 & 13.4 & 0.2 & -0.6 & 0.9 & & & \\
\hline \multirow[t]{4}{*}{ PABS } & Biomedical & 35.3 & 25.7 & 9.6 & 7.6 & 11.7 & 11.0 & 8.2 & 13.8 \\
\hline & Biomedical & 34.8 & 36.2 & -1.4 & -3.4 & 0.6 & & & \\
\hline & Behavioural & 29.9 & 35.0 & -5.1 & -7.4 & -2.9 & -3.5 & -6.3 & -0.6 \\
\hline & Behavioural & 29.6 & 31.2 & -1.7 & -3.5 & 0.2 & & & \\
\hline
\end{tabular}

Intervention group $(\mathrm{n}=23)$

Control group $(n=22)$

\section{Outcome measures}

In the main trial, PABS on its own could be used as both questionnaires showed similar changes and the PABS permits comparing findings with other studies.

\section{E-learning acceptability}

The acceptability of both the content and the instructional method was overall good.

Participants valued the Extra Content Folder; the fact that the content was evidence-based rather than experiential and that references were listed. One participant mentioned in their semi-structured interview a need for an easier system to contact the lecturer than email. As participants valued the autonomy they had whilst taking the course over the 6-week period with no constraints on time, place, or from other participants, asynchronous collaboration and communication tools (e.g. emails and forums) would therefore probably be easier and more appropriate to implement than synchronous tools (e.g. live instant messages and live broadcasts) in an improved version of the e-learning programme. This would also be better educational tools as using those asynchronous format in e-learning programmes for postgraduate studies promotes self-reflection [67] leading to deeper learning than e-learning programmes using a synchronous format [46].

\section{Content acceptability}

The content satisfaction was high due partly to the content being evidence-based rather than experience-based or anecdotal which provided participants with clear tools and approaches to discuss management options with patients (e.g. the possible innocuousness of some MRI findings). This was also reported in another study that assessed what participants found helpful to change their attitudes to back pain [56].

Whilst participants generally reported that nothing was missing from the e-learning content, there was overall agreement that more information on how to implement a BPS management of patients with NSLBP was required (developed in Unit 5 of the e-learning programme). Participants suggested that this information should be developed in a different e-learning programme, as the one developed in this study already contained a lot of content.

\section{E-learning programme impact and contextualisation}

There is currently no definition of what constitutes a high or low score on the ABS-mp or PABS domains, making it difficult to quantify a clinically relevant attitudinal change [52] but results from our mixed methods feasibility study were consistent with scores found in previous studies that also used the PABS [6, 25, 30, 32, 33, 35, 59]. Participants in this study had slightly higher biomedical scores and lower behavioural scores than Houben et al.'s participants (2005, 2005). Participants included in the study were experienced osteopaths whereas Houben et al.'s participants were either physiotherapy students or physiotherapists with an average of 
12 years of work experience. This is consistent with results in a study that found that the more experienced GPs are, the more likely they are to have high biomedical levels [25].

The intervention group in our study showed changes in scores on the PABS domains after an 8-h e-learning programme: the biomedical score decreased and the behavioural score increased. Those changes were significant when compared to two studies that also used PABS as their outcome measurement questionnaire [4, 59]. The effect size of the intervention was large on both PABS subscales (2.4 for the biomedical subscale and 0.75 for the behaviour) but caution would be required if these findings were used in a main trial due to limitations in using feasibility studies to provide precise between treatment group effect size estimates [1, 14, 40, 43].

\section{Strengths and limitations}

This feasibility study was the first to assess osteopaths' views on using e-learning as a form of $C P D$ and their views on the BPS model. The design followed best practice: the MRC's recommendations for the development and evaluation of complex interventions were followed. Guidance on good practice for conducting feasibility studies and for conducting explanatory mixed methods were also followed. Several methods were employed to assess and ensure the study quality $[37,65]$. It also provided new insights on methods to assess practitioners' views.

The quantitative results showed an unexpectedly high level of satisfaction with the course and the content leading to the inclusion of specific questions in the semi-structured interviews to explore more deeply participants' views on the biopsychosocial model in practice. In a main trial, the satisfaction survey could be sent a few weeks after completing the course in order to gather data on participants' experience in implementing the content in clinical practice.

Whilst the intervention validity was carefully considered and its content informed by the scoping review results $[19,20]$, the validity of the scenarios would need to be considered: they were written by the researcher based on his clinical experience, and on theoretical aspects important for understanding pain mechanisms. Using an expert panel to assess their validity would be appropriate and exchanging the ones used for real-case scenarios that would be used to film professional actors or real patients, whilst considering ethical implications, could enhance their validity.

As there is not a clear-cut point when the integration of the BPS model started in Osteopathic Educational Institutions' curricula, the inclusion criteria might have limited the recruitment rate. The recruitment rate was lower than expected (45 instead of 50): whilst this may not have a large impact on the findings on the feasibility of running a main trial, it is suggestive of a highly selective sample that was possibly keen on taking a course online.

Measuring knowledge could have been a useful outcome but there are no existing instruments assessing knowledge of the biopsychosocial model and the closest existing tools lack evidence regarding their reliability, e.g. the Pain Neurophysiology Questionnaire [51]. If additional questionnaires were used in a main trial, participants' burden should be carefully considered. The purposeful absence of knowledge of the participants' prior BPS training at recruitment could have confounded the results as groups may not have been successfully balanced by randomisation. However, to some extent this is mitigated by the similar baseline characteristics of both groups as measured by the PABS and ABS-MP. In a main trial, collection of prior exposure to BPS training after participant enrolment could effectively enable the assessment of BPS education at recruitment being unbalanced and confounding the results.

The breach of eligibility criteria (i.e. including two participants with 14 years of experience) would not be possible in a main trial and considerations about eligibility criteria is paramount.

The external validity of the findings on using elearning as a form of CPD might be limited, as participants in the study did not pay to take the e-learning programme. Their satisfaction rating or acceptability of the intervention could have been different if a fee had been paid. The design of a main trial would need to include blinding of outcome assessors and data analysis and will need further consideration as a pragmatic trial comparing the effectiveness of the e-learning delivery compared to face-to-face delivery may provide insightful comparative data. This would require further feasibility testing. In order to use the e-learning programme in a main trial, updating the content would be required but it would be largely suitable. Recent surveys of osteopaths in the UK suggest that there is a need to enhance osteopaths' BPS dispositions [3, 44]. Updating the e-learning programme is anticipated only to require a limited amount of work; therefore, the resources required in a main trial are expected to be similar to those required in this feasibility study.

\section{Conclusion}

This mixed methods feasibility study supports that conducting an RCT would be feasible: the recruitment procedure, randomisation process and data collection were found feasible to use in a main trial. The sample was composed of experienced practitioners and the intervention was overall very well accepted. Using real scenarios or discussing the clinical scenarios with experts should 
be considered to improve the e-learning programme validity. The study followed recommendations on the conducting of mixed methods explanatory design and there were clear strategies implemented to ensure the quantitative and qualitative data quality.

\section{Abbreviations}

ABS-mp: Attitudes to Back pain Scale for musculoskeletal practitioners; LS: Limitations on sessions; PS: Psychology; CHS: Connection to Health care System; CC: Confidence and concern; RA: Reactivation; BM: Biomedical; BPS: Biopsychosocial; UCO: University College of Osteopathy; Cl: Confidence interval; CPD: Continuous professional development; IQR: Interquartile range; IT: Information technology; LBP: Low back pain; MRC: Medical Research Council; NCOR: National Council for Osteopathic Research; NSLBP: Nonspecific low back pain; PABS: Pain Attitudes and Beliefs Scale; PS: Psychosocial; RCT: Randomised controlled trial; SD: Standard deviation

\section{Supplementary Information}

The online version contains supplementary material available at https://doi. org/10.1186/s40814-021-00901-4

\section{Additional file 1.}

Additional file 2.

\section{Acknowledgements}

Dr. Hilary Abbey for her support in the statistical analysis and interpretation.

\section{Authors' contributions}

JDR, SV and AB developed the idea. JDR conducted the trial and analysed the data. JDR, SV and $A B$ met regularly to discuss the progress. JDR wrote the first draft and $S V$ and $A B$ provided comments and changes to the manuscript. All authors read and approved the final manuscript.

\section{Authors' information}

This work was part of JDR's research towards a doctoral award.

\section{Funding}

Research partially funded by the University College of Osteopathy

\section{Availability of data and materials}

Available as supporting evidence to the paper in two files

\section{Declarations}

\section{Ethics approval and consent to participate}

The research was approved by the University College of Osteopathy Research Ethics Committee.

\section{Consent for publication}

Not applicable

\section{Competing interests}

The authors declare that they have no competing interests.

\section{Author details}

${ }^{1}$ University College of Osteopathy, 275 Borough High Street, London SE1 1JE, UK. ${ }^{2}$ Arthritis Research UK Primary Care Centre, Research Institute Primary Care Sciences, Keele University, Staffordshire ST5 5BG, UK.

Received: 27 March 2020 Accepted: 10 August 2021

\section{Published online: 13 September 2021}

\section{References}

1. Arain, M., et al. (2010). "What is a pilot or feasibility study? A review of current practice and editorial policy." BMC Med Res Methodol 10(67): [Online] Available at: http://www.biomedcentral.com/1471-2288/1410/1467.

2. Asenlof $P$, et al. Long-term follow-up of tailored behavioural treatment and exercise based physical therapy in persistent musculoskeletal pain: a randomized controlled trial in primary care. Eur J Pain. 2009;13(10):1080-8. https://doi.org/10.1016/j.ejpain.2009.01.010.

3. Bar-Zaccay A, Bailey D. The attitudes and beliefs of UK osteopaths towards the management of low back pain: a cross-sectional study. Int J Osteopathic Med. 2018;28:42-7. https://doi.org/10.1016/j.ijosm.2018.03.006.

4. Beneciuk J, George S. Pragmatic implementation of a stratified primary care model for low back pain management in outpatient physical therapy settings: two-Pphase, sequential preliminary study. Phys Ther. 2015;95(8): 1120-34. https://doi.org/10.2522/ptj.20140418.

5. $\quad$ Bishop A. Pain attitudes and beliefs scale (PABS). J Physiother. 2010;56(4): 279. https://doi.org/10.1016/S1836-9553(10)70014-X.

6. Bishop A, Foster NE, Thomas E, Hay EM. How does the self-reported clinical management of patients with low back pain relate to the attitudes and beliefs of health care practitioners? A survey of UK general practitioners and physiotherapists. Pain. 2008;135(1-2):187-95. https://doi.org/10.1016/j.pain.2 007.11.010.

7. Bishop AT, Foster E, NE. Health care practitioners' attitudes and beliefs about low back pain: a systematic search and critical review of available measurement tools. Pain. 2007;132(1-2):91-101. https://doi.org/10.1016/j.pa in.2007.01.028.

8. Bowey-Morris J, Purcell-Jones G, Watson PJ. Test-retest reliability of the pain attitudes and beliefs scale and sensitivity to change in a general practitioner population. Clin J Pain. 2010;26(2):144-52. https://doi.org/10.1097/AJP.0b013 e3181bada3d.

9. Braun V, Clarke V. Using thematic analysis in psychology. Qual Res Psychol. 2006;3(2):77-101. https://doi.org/10.1191/1478088706qp063oa.

10. Braye $\mathrm{S}$, et al. Building collaborative capacity for using and evaluating the impact of e-learning in social work education: the case of law. Soc Work Educ. 2013;33(6):835-53.

11. Buchbinder R, Staples M, Jolley D. Doctors with a special interest in back pain have poorer knowledge about how to treat back pain. Spine. 2009; 34(11):1218-27. https://doi.org/10.1097/BRS.0b013e318195d688.

12. Burton AK, et al. Chapter 2 European guidelines for prevention in low back pain, November 2004 [with consumer summary]. Eur Spine J. 2006;15(Suppl 2):S136-68. https://doi.org/10.1007/s00586-006-1070-3.

13. Cholewicki J, et al. (2019). "Model simulations challenge reductionist research approaches to studying chronic low back pain." J Orthopaedic Sports Physical Ther 49(6): 477-481.

14. Cocks K, Torgerson DJ. Sample size calculations for pilot randomized trials: a confidence interval approach. J Clin Epidemiol. 2013;66(2):197-201. https:// doi.org/10.1016/j.jclinepi.2012.09.002.

15. Craig, P., et al. (2008). "Developing and evaluating complex interventions: the new Medical Research Council guidance." BMJ 337(a1655): [Online] Available at: http://www.bmj.com/content/337/bmj.a1655.

16. Creswell JW. Educational research: planning, conducting, and evaluating quantitative and qualitative research. 4th ed. NJ: Merrill Prentice Hall; 2012.

17. Creswell JW, Clark VLP. Designing and conducting mixed methods research. California: Sage Publications, Inc.; 2011.

18. Cutting MF, Saks NS. Twelve tips for utilizing principles of learning to support medical education. Med Teach. 2012;34(1):20-4. https://doi.org/1 $0.3109 / 0142159 \times 2011.558143$.

19. Draper-Rodi J, Vogel S, Bishop A. Design and development of an e-learning programme: an illustrative commentary. Int J Osteopathic Med. 2018a;29: 36-40. https://doi.org/10.1016/j.ijosm.2018.07.002.

20. Draper-Rodi J, Vogel S, Bishop A. Identification of prognostic factors and assessment methods on the evaluation of non-specific low back pain in a biopsychosocial environment: a scoping review. Int J Osteopathic Med. 2018b;30:25-34. https://doi.org/10.1016/j.ijosm.2018.07.001.

21. Egbewale BE. Statistical issues in randomised controlled trials: a narrative synthesis. Asian Pac J Trop Biomed. 2015;5(5):354-9. https://doi.org/10.1016/ S2221-1691(15)30367-1.

22. Fletcher, B., et al. (2012). "Improving the recruitment activity of clinicians in randomised controlled trials: a systematic review." BMJ Open 2(1): [Online] Available at: http://bmjopen.bmj.com/content/2/1/e000496.full.

23. Freeth, D. M., P. Carnes, D. (2012). New graduates' preparedness to practice: research report of a study commissioned by the General Osteopathic Council. Available from http://www.osteopathy.org.uk/uploads/new_gradua tes_preparedness_to_practise_report_2012.pdf.

24. Formica A, et al. "I just don't have the tools' - Italian osteopaths' attitudes and beliefs about the management of patients with chronic pain: A qualitative study." Int J Osteopathic Med. 2018;27:6-13. 
25. Fullen B, et al. General practitioners attitudes and beliefs regarding the management of chronic low back pain in Ireland. Clin J Pain. 2011; 27(6):180-9.

26. Green CA, Duan N, Gibbons RD, Hoagwood KE, Palinkas LA, Wisdom JP. Approaches to mixed methods dissemination and implementation research: methods, strengths, caveats, and opportunities. Adm Policy Ment Health. 2015;42(5):508-23. https://doi.org/10.1007/s10488-014-0552-6.

27. Green DJ, Lewis M, Mansell G, Artus M, Dziedzic KS, Hay EM, et al. Clinical course and prognostic factors across different musculoskeletal pain sites: a secondary analysis of individual patient data from randomised clinical trials. Eur J Pain. 2018;22(6):1057-70. https://doi.org/10.1002/ejp.1190.

28. Halcomb EJ, Davidson PM. Is verbatim transcription of interview data always necessary? Appl Nurs Res. 2006;19(1):38-42. https://doi.org/10.1016/j.apnr.2 005.06.001.

29. Hay E, Mullis R, Lewis M, Vohora K, Main CJ, Watson P, et al. Comparison of physical treatments versus a brief pain-management programme for back pain in primary care: a randomised clinical trial in physiotherapy practice. Lancet. 2005;365(9476):2024-30. https://doi.org/10.1016/S0140-673 6(05)66696-2.

30. Hendrick P, Mani R, Bishop A, Milosavljevic S, Schneiders AG. Therapist knowledge, adherence and use of low back pain guidelines to inform clinical decisions--a national survey of manipulative and sports physiotherapists in New Zealand. Man Ther. 2013;18(2):136-42. https://doi. org/10.1016/j.math.2012.09.002

31. Hill JC, Whitehurst DGT, Lewis M, Bryan S, Dunn KM, Foster NE, et al. Comparison of stratified primary care management for low back pain with current best practice (STarT Back): a randomised controlled trial. Lancet. 2011;378(9802):1560-71. https://doi.org/10.1016/S0140-6736(11)60937-9.

32. Houben RM, et al. Health care providers' orientations towards common low back pain predict perceived harmfulness of physical activities and recommendations regarding return to normal activity. Eur J Pain. 2005a;9(2): 173-83. https://doi.org/10.1016/j.ejpain.2004.05.002

33. Houben RMA, Gijsen A, Peterson J, de Jong PJ, Vlaeyen JWS. Do health care providers' attitudes towards back pain predict their treatment recommendations? Differential predictive validity of implicit and explicit attitude measures. Pain. 2005b;114(3):491-8. https://doi.org/10.1016/j.pain.2005.01.017.

34. Houghton C, Casey D, Shaw D, Murphy K. Rigour in qualitative case-study research. Nurse Res. 2013;20(4):12-7. https://doi.org/10.7748/nr2013.03.2 0.4.12.e326.

35. Innes, S. I., et al. (2015). "Attitudes and beliefs of Australian chiropractors' about managing back pain: a cross-sectional study." Chiropractic Man Therapies 23(17): [Online] Available at: http://chiromt.biomedcentral.com/a rticles/10.1186/s12998-12015-10062-y.

36. Ivan L, et al. What does best practice care for musculoskeletal pain look like? Eleven consistent recommendations from high-quality clinical practice guidelines: systematic review. Br J Sports Med. 2019.

37. Ivankova NV. Implementing quality criteria in designing and conducting a sequential QUAN -> QUAL mixed methods study of student engagement with learning applied research methods online. J Mixed Methods Res. 2013; 8(1):25-51.

38. Jellema $\mathrm{P}$, van der Windt DAWM, van der Horst HE, Blankenstein AH, Bouter LM, Stalman WAB. Why is a treatment aimed at psychosocial factors not effective in patients with (sub)acute low back pain? Pain. 2005;118(3):350-9. https://doi.org/10.1016/j.pain.2005.09.002.

39. Klímová B. Mobile learning in medical education. J Med Syst. 2018;42(10): 194. https://doi.org/10.1007/s10916-018-1056-9.

40. Kraemer HC, Mintz J, Noda A, Tinklenberg J, Yesavage JA. Caution regarding the use of pilot studies to guide power calculations for study proposals. Arch Gen Psychiatry. 2006;63(5):484-9. https://doi.org/10.1001/archpsyc.63.5.484.

41. Lancaster GA. Pilot and feasibility studies come of age! Pilot Feasibility Stud. 2015;1(1):1-4. https://doi.org/10.1186/2055-5784-1-1.

42. Lancaster GA, Dodd S, Williamson PR. Design and analysis of pilot studies: recommendations for good practice. J Eval Clin Pract. 2004;10(2):307-12. https://doi.org/10.1111/j..2002.384.doc.x.

43. Leon AC, Davis LL, Kraemer HC. The role and interpretation of pilot studies in clinical research. J Psychiatr Res. 2011;45(5):626-9. https://doi.org/10.1016/ j.jpsychires.2010.10.008

44. Macdonald $\mathrm{R}$, et al. The beliefs and attitudes of UK registered osteopaths towards chronic pain and the management of chronic pain sufferers-a cross-sectional questionnaire based survey. Int J Osteopathic Med. 2018;30: 3-11. https://doi.org/10.1016/j.ijosm.2018.07.003.
45. McGivern, G., et al. (2015). A review of literature on the osteopathic profession, osteopathic practice and osteopathic regulation in the UK, General Osteopathic Council.

46. Means, B., et al. (2009). Evaluation of evidence-based practices in online learning: a meta-analysis and review of online learning studies. U.S. Department of Education. Washington D.C

47. Michie S. The behaviour change wheel: a method for designing effective interventions. Dublin: Implementation Science Summer School; 2012.

48. Michie, S., et al. (2011). "Strengthening evaluation and implementation by specifying components of behaviour change interventions: a study protocol." Implementation Sci 6(10): [Online] Available at: https:// implementationscience.biomedcentral.com/articles/10.1186/1748-5908-11 86-1110.

49. Moher D, Hopewell S, Schulz KF, Montori V, Gøtzsche PC, Devereaux PJ, et al. CONSORT 2010 explanation and elaboration: updated guidelines for reporting parallel group randomised trials. J Clin Epidemiol. 2010;63(8):e137. https://doi.org/10.1016/j.jclinepi.2010.03.004

50. Moore CG, Carter RE, Nietert PJ, Stewart PW. Recommendations for planning pilot studies in clinical and translational research. Clin Transl Sci. 2011;4(5):332-7. https://doi.org/10.1111/j.1752-8062.2011.00347.x.

51. Moseley L. Unraveling the barriers to reconceptualization of the problem in chronic pain: the actual and perceived ability of patients and health professionals to understand the neurophysiology. The J Pain. 2003;4(4):184-9.

52. Mutsaers $\mathrm{JH}$, et al. Psychometric properties of the pain attitudes and beliefs scale for physiotherapists: a systematic review. Man Ther. 2012;17(3):213-8. https://doi.org/10.1016/j.math.2011.12.010.

53. Namey, E., et al. (2008). Data reduction techniques for large qualitative data sets. Handbook for team-based qualitative research. G. Guest and K. M. McQueen. Plymouth (UK), Rowman Altamira: 137-161.

54. National Institute for Health and Care Excellence. Low back pain: early management of persistent non-specific low back pain. London: National Institute for Health and Clinical Excellence; 2009

55. National Institute for Health and Care Excellence. Low back pain and sciatica: management of non-specific low back pain and sciatica. In: National Clinical Guideline Centre. London: National Institute for Health and Clinical Excellence; 2016.

56. O'Sullivan K, et al. Back pain beliefs among physiotherapists are more positive after biopsychosocially orientated workshops. Physiother Pract Res. 2013:34(1):37-45.

57. Ostelo RWJG, Stomp-van den Berg SGM, Vlaeyen JWS, Wolters PMJC, de Vet HCW. Health care provider's attitudes and beliefs towards chronic low back pain: the development of a questionnaire. Man Ther. 2003;8(4):214-22 https://doi.org/10.1016/S1356-689X(03)00013-4.

58. Overmeer T, Boersma K, Denison E, Linton SJ. Does teaching physical therapists to deliver a biopsychosocial treatment program result in better patient outcomes? A randomized controlled trial. Phys Ther. 2011;91(5):80419. https://doi.org/10.2522/ptj.20100079.

59. Overmeer T, Boersma K, Main CJ, Linton SJ. Do physical therapists change their beliefs, attitudes, knowledge, skills and behaviour after a biopsychosocially orientated university course? J Eval Clin Pract. 2009;15(4): 724-32. https://doi.org/10.1111/j.1365-2753.2008.01089.x.

60. Pincus T, Vogel S, Santos R, Breen A, Foster N, Underwood M. The attitudes to back pain scale in musculoskeletal practitioners (ABS-mp) - the development and testing of a new questionnaire. Clin J Pain. 2006;22(4): 378-86. https://doi.org/10.1097/01.ajp.0000178223.85636.49.

61. Ramond A, Bouton C, Richard I, Roquelaure Y, Baufreton C, Legrand E, et al. Psychosocial risk factors for chronic low back pain in primary care--a systematic review. Fam Pract. 2011;28(1):12-21. https://doi.org/10.1093/fa mpra/cmq072.

62. Richmond $\mathrm{H}$, et al. (2016). "Using mixed methods evaluation to assess the feasibility of online clinical training in evidence based interventions: a case study of cognitive behavioural treatment for low back pain." BMC Med Educ 16(1)(163).

63. Roots SA, Niven E, Moran RW. Osteopaths' clinical reasoning during consultation with patients experiencing acute low back pain: a qualitative case study approach. Int J Osteopathic Med. 2016;19:20-34. https://doi.org/1 0.1016/j.josm.2015.06.003.

64. Sacristán JA. Patient-centered medicine and patient-oriented research: improving health outcomes for individual patients. BMC Med Inform Decis Mak. 2013;13(1):1-8 
65. Shenton A. Strategies for ensuring trustworthiness in qualitative research projects. Educ Information. 2004;22(2):63-75. https://doi.org/10.3233/EFl-2 004-22201.

66. Sim J, Lewis M. The size of a pilot study for a clinical trial should be calculated in relation to considerations of precision and efficiency. J Clin Epidemiol. 2012;65(3):301-8. https://doi.org/10.1016/j.jclinepi.2011.07.011.

67. Sinclair PM, Kable A, Levett-Jones T, Booth D. The effectiveness of Internetbased e-learning on clinician behaviour and patient outcomes: a systematic review. Int J Nurs Stud. 2016;57:70-81. https://doi.org/10.1016/j.jnurstu.2016. 01.011.

68. Singla $\mathrm{M}$, et al. "Physiotherapists' assessment of patients' psychosocial status: Are we standing on thin ice? A qualitative descriptive study." Manual Therapy. 2015;20(2):328-34.

69. Stevenson K, Lewis M, Hay E. Does physiotherapy management of low back pain change as a result of an evidence-based educational programme? J Eval Clin Pract. 2006;12(3):365-75. https://doi.org/10.1111/j.1365-2753.2006. 00565.x.

70. Sullivan MJ, Adams H. Psychosocial treatment techniques to augment the impact of physiotherapy interventions for low back pain. Physiother Can. 2010;62(3):180-9. https://doi.org/10.3138/physio.62.3.180.

71. Synnott A, et al. "Physiotherapists may stigmatise or feel unprepared to treat people with low back pain and psychosocial factors that influence recovery: a systematic review." J Physiother. 2015;61(2): 68-76.

72. Teare, M., et al. (2014). "Sample size requirements to estimate key design parameters from external pilot randomised controlled trials: a simulation study." Trials 15(264): [Online] Available at: http://www.trialsjournal.com/ content/15/11/264.

73. Thabane, L., et al. (2010). "A tutorial on pilot studies: the what, why and how." BMC Med Res Methodol 10(1): [Online] Available at: http://www. biomedcentral.com/1471-2288/1410/1471.

74. Treweek, S., et al. (2013). "Methods to improve recruitment to randomised controlled trials: Cochrane systematic review and meta-analysis." BMJ Open 3(2): [Online] Available at: http://bmjopen.bmj.com/content/3/2/e002360.full.

75. Valjakka AL, Salanterä S, Laitila A, Julkunen J, Hagelberg NM. The association between physicians' attitudes to psychosocial aspects of low back pain and reported clinical behaviour: a complex issue. Scand J Pain. 2013;4(1):25-30. https://doi.org/10.1016/.spain.2012.08.003.

76. van Erp RMA, Huijnen IPJ, Jakobs MLG, Kleijnen J, Smeets RJEM. Effectiveness of primary care interventions using a biopsychosocial approach in chronic low back pain: a systematic review. Pain Pract. 2019; 19(2):224-41. https://doi.org/10.1111/papr.12735.

77. van Griensven H, Moore AP, Hall V. Mixed methods research - the best of both worlds? Man Ther. 2014;19(5):367-71. https://doi.org/10.1016/.math.2 014.05.005.

78. Vibe Fersum K, O'Sullivan P, Skouen JS, Smith A, Kvåle A. Efficacy of classification-based cognitive functional therapy in patients with nonspecific chronic low back pain: a randomized controlled trial. Eur J Pain. 2013;17(6):916-28. https://doi.org/10.1002/j.1532-2149.2012.00252.x.

79. Vibe Fersum K, Smith A, Kvåle A, Skouen JS, O'Sullivan P. Cognitive functional therapy in patients with non-specific chronic low back pain-a randomized controlled trial 3-year follow-up. Eur J Pain. 2019;23(8):1416-24. https://doi.org/10.1002/ejp.1399.

80. Waddell G. 1987 Volvo award in clinical sciences. A new clinical model for the treatment of low-back pain. Spine J. 1987;12(7):632-44. https://doi.org/1 0.1097/00007632-198709000-00002.

81. Waddell G, Aylward M. Models of sickness and disability: applied to common health problems. London: Royal Society of Medicine; 2009

82. Zangoni G, Thomson OP. "'I need to do another course' - Italian physiotherapists' knowledge and beliefs when assessing psychosocial factors in patients presenting with chronic low back pain." Musculoskelet Sci Pract. 2017;27:71-7.

\section{Publisher's Note}

Springer Nature remains neutral with regard to jurisdictional claims in published maps and institutional affiliations.

\section{Ready to submit your research? Choose BMC and benefit from}

- fast, convenient online submission

- thorough peer review by experienced researchers in your field

- rapid publication on acceptance

- support for research data, including large and complex data types

- gold Open Access which fosters wider collaboration and increased citations

- maximum visibility for your research: over $100 \mathrm{M}$ website views per year

At BMC, research is always in progress.

Learn more biomedcentral.com/submissions 